\title{
Edible insects and food safety: allergy
}

\author{
J.C. Ribeiro ${ }^{1}$, B. Sousa-Pinto ${ }^{2,3,4}$, J. Fonseca ${ }^{2,4,5}$, S. Caldas Fonseca ${ }^{1}$ and L.M. Cunha $^{1 *}$ \\ ${ }^{1}$ GreenUPorto - Sustainable Agrifood Production Research Centre, DGAOT, Faculty of Sciences, University of Porto, \\ Campus de Vairão, Rua da Agrária 747, 4485-646 Vila do Conde, Portugal; ${ }^{2}$ MEDCIDS - Department of Community \\ Medicine, Information and Health Decision Sciences, Faculty of Medicine, University of Porto, Rua Dr. Plácido da Costa, \\ 4200-450 Porto, Portugal; ${ }^{3}$ Laboratory of Immunology, Basic and Clinical Immunology Unit, Faculty of Medicine, University \\ of Porto, Rua Dr. Plácido da Costa, 4200-450 Porto, Portugal; ${ }^{4}$ CINTESIS - Centre for Health Technology and Services \\ Research, Rua Dr. Plácido da Costa, s/n 4200-450 Porto, Portugal; ${ }^{5}$ Allergy Unit, CUF Porto Institute \& Hospital, Estrada \\ da Circunvalação 14341, 4100-180 Porto, Portugal; lmcunha@fc.up.pt
}

Received: 30 June 2020 / Accepted: 6 November 2020

(c) 2021 Wageningen Academic Publishers

OPEN ACCESS (C) (1) (9) (2)

REVIEW ARTICLE

\begin{abstract}
Edible insects are a unique food source, requiring extensive allergenic risk assessment before its safe introduction in the food market. In a recent systematic review, crustacean allergic subjects were identified as a risk group due to cross-reactivity mainly mediated by tropomyosin and arginine kinase. Immunologic co-sensitisation to house dust mites (HDM) was also demonstrated, but its clinical significance and molecular mechanisms were unclear. Furthermore, case reports of food allergy to insects were also analysed but lack of contextual information hindered the analysis. The main goal of this review is to provide an update of new information regarding food allergy caused by insects, covering relevant topics considering the guidelines for allergic risk assessment in novel foods. Newly published studies have further confirmed the role of tropomyosin as a cross-reactive allergen between edible insects and crustaceans, although there are some questions regarding the immunoglobulin E (IgE)-reactivity of this allergen in mealworm species. Furthermore, only specific treatments (enzymatic hydrolysis combined with thermal treatments) were able to eliminate IgE-reactivity of edible insects. Primary sensitisation (e.g. to Tenebrio molitor) has also been shown to be an important pathway for the development of food allergies, with responsible allergens being dependent on the route of sensitisation. However, more studies are necessary to better understand the potential of primary sensitisation causing cross-reactivity with other insect species, crustaceans or HDM. The clinical significance and molecular mechanisms involved in cross-reactivity between edible insects and HDM are still unclear, and a major focus should be given to better understand which allergens cause co-sensitisations between HDM and edible insects and what is the risk of HDM-only allergic subjects consuming edible insects. Contextual information about the reported cases of allergic reactions to insects have further demonstrated that insect-rearing workers and subjects with allergic diseases (in particular, food allergy to crustaceans) are the major risk groups.
\end{abstract}

Keywords: case reports, cross-reactivity, entomophagy, primary sensitisation, tropomyosin

\section{Introduction}

Immunoglobulin-E (IgE)-mediated food allergy can be described as an adverse reaction of the immune system to specific proteins in foods which are usually harmless (De Gier and Verhoeckx, 2018; Messina and Venter, 2020). It is estimated that $3-10 \%$ of adults and $8 \%$ of children worldwide have a food allergy, with most reactions being caused by milk, egg, peanut, tree nuts, fish, soy, wheat or crustaceans (Boyce et al., 2010; Messina and Venter, 2020). These IgE-mediated reactions occur after the consumption of the food product with an onset of up to 2 hours after the consumption, with their presentations ranging from isolated cutaneous or abdominal symptoms to potential fatal reactions such as anaphylaxis (Wang and Sampson, 2011). Food allergies are developed in two phases. Firstly, in the sensitisation phase, susceptible individuals are exposed to an allergen (usually through 
consumption) and produce specific IgE antibodies to that allergen. Afterwards, following repeated exposure to the same allergen, IgE antibodies on the surface of mast cells recognise the specific allergen, cross-link, and activate an immunologic response (Muraro et al., 2014). However, reactions can also occur due to cross-reactivity, which is defined as when IgE antibodies originally raised against one allergen bind to another structurally-related allergen. Cross-reactivity occurs frequently between allergens from taxonomically related species due to the existence of panallergens (proteins that are highly preserved from an evolutionary point of view, and capable of inducing allergic responses in related species) (García and Lizaso, 2011; Migueres et al., 2014). In order to confirm cross-reactivity it is usually necessary to perform inhibition assays, otherwise it is recommended to use the term co-sensitisation, which consists on the simultaneous presence of different IgEs that bind to allergens that may not necessarily have common structural features (Migueres et al., 2014).

Allergic reactions subsequent to insect consumption can be associated to cross-reactivity. This reaction may occur due to the phylogenetic relationship of insects with common allergen sources such as crustaceans or house dust mites (HDM) (Pennisi, 2015). In fact, cross-reactivity with crustaceans has been demonstrated to be clinically relevant, with the main cross-reacting allergens identified being the arthropod pan-allergens tropomyosin and arginine kinase (AK). On the other hand, co-sensitisation between edible insects and HDM has been shown, but the underlying molecular mechanisms and clinical significance remain unclear. Allergic reactions to edible insects can also be associated to primary sensitisation (either through environmental (Pomés et al., 2017) or occupational (Stanhope et al., 2015) exposure) - several allergens have been already identified and characterised, namely AK (cockroaches, silkworm and indianmeal moth), tropomyosin (cockroaches, mosquito, termite, silverfish), aspartic protease, hemocyanin, glutathione $S$-transferase, troponin $C$, myosin light chain, serine protease and $\alpha$-amylase (cockroaches). Moreover, edible insect allergens were reported to have similar behaviours to crustacean allergens in response to enzymatic and thermal treatments (De Gier and Verhoeckx, 2018; Jeong and Park, 2020; Ribeiro et al., 2018). While epidemiological data and even case reports are still scarce, and often lacking in contextual information (De Gier and Verhoeckx, 2018; Ribeiro et al., 2018), there have been reports indicating that insects are responsible for 4.2-19.4\% of cases of food allergies in Asian countries (Ribeiro et al., 2018), and that silkworm pupae is a major culprit of food allergies in China (Ji et al., 2008) and Korea (Jeong and Park, 2020).

The legal status of edible insects as a novel food (Belluco et al., 2017) prompts the need for an in-depth risk assessment - including the allergenic risk - so that they can be commercialised in the European Union food market. Although there is not any established protocol for allergenicity assessment of novel foods, the current guidelines are based on weight-of-evidence approach, taking into account such different issues as: (1) the history of allergic reactions to the novel food; (2) the taxonomy of the novel food (to identify possible relations with known allergic sources); and (3) the identification and characterisation of proteins of the novel food (with assessment of their allergenic potential through bioinformatics assays, comparing them to known allergens). In addition, the IgEbinding capacity of the novel food has also to be assessed, using serum form individuals allergic to other sources (for cross-reactivity) or serum from individuals sensitised to the novel food (primary sensitisation). It is also important to identify possible IgE-binding proteins and to determine the biological activity of such proteins (if they can activate an immunologic response), either through functional tests (such as basophil activation tests; BAT) or food challenges. Further tests also include the evaluation of thermal and chemical (e.g. resistance to enzymatic digestion) treatments on the allergenic properties of a novel food.(Mazzucchelli et al., 2018; Verhoeckx et al., 2016; Westerhout et al., 2019).

The relative novelty of this theme implies that new information is being constantly published, and that the state of the art needs to be updated frequently. Therefore, in this study, we aim to update our previous review (Ribeiro et al., 2018), assessing the new scientific developments related to the allergic risks of insects as food. Specifically, we aimed to cover all the relevant topics related to allergic risk assessment of edible insects including the mechanisms and allergens implied both in primary sensitisation and in cross-reactivity with crustaceans or HDM and the effects of food processing on edible insects' allergenicity. In addition, we aimed to assess epidemiological studies and case series/ reports of allergic reactions following insect consumption.

\section{Methods}

The methodology applied in this study was based on the previous systematic review performed by the authors (Ribeiro et al., 2018). In brief, a systematic search was conducted on three online databases (PubMed/Medline, Scopus and Web of Science) on May 2020 using the same query - (insect OR mite* OR carmine OR cochineal OR cockroach OR arthropod OR crustacea* OR silkworm OR locust OR grasshopper OR cricket OR mealworm OR moth OR beetle) AND (allerg* OR hypersensitiv* OR anaphyla* OR crossreactiv*) AND (food OR edible OR consumption OR entomophagy OR ingesti* OR occupati* OR consum* OR eat*). In order to avoid obtaining previously reviewed papers, only articles published since 2017 were retrieved on this database search. References of included studies and review papers concerning entomophagy were also screened. 


\section{Inclusion and exclusion criteria}

In accordance with our aims, in this systematic review we sought to cover all the relevant topics regarding edible insects allergenicity according to current guidelines for novel food allergenic risk assessment. Therefore, we included original studies that assessed cross-reactivity or co-sensitisation between edible insects and crustaceans or HDM, as well as the molecular mechanisms in food primary sensitisation to edible insects. Moreover, articles identifying and characterising (including effects of food processing techniques) food allergens from edible insects were also included. Additionally, case reports describing allergic reactions following the intentional ingestion of insects, and studies assessing the prevalence of such reactions were also included.

We excluded articles that only assessed other types of insect allergies (e.g. respiratory allergy or reactions subsequent to stings or bites) as well as articles characterising allergens from non-edible insects (e.g. cockroaches). Additionally, articles included in our previous systematic review were also excluded.

\section{Study selection and data extraction}

After duplicates removal, the retrieved studies were firstly screened by title and abstract, and then by full-text reading. The full texts of studies meeting the inclusion criteria were analysed, and information was retrieved on May 2020.

The whole process for study selection and data extraction was independently performed by two authors, and any disagreement was solved by consensus.

\section{Results}

A total of 20 articles were included in this systematic review - 19 obtained through database research and 1 (Jiang et al., 2016) obtained through screening of the references of included studies (although it was published in 2016, it was included since it was not present in our previous review) (Figure 1).

Of these 20 articles, 8 studied cross-reactivity or cosensitisation with either crustaceans or HDM (Barre et al., 2019; Beaumont et al., 2019; Broekman et al., 2017a; Hall et al., 2018; Kamemura et al., 2019; Pali-Scholl et al., 2019; Palmer et al., 2020; Sokol et al., 2017), 5 focused on primary sensitisation (Broekman et al., 2017a,b; Francis et al., 2019; Jeong et al., 2017; Nebbia et al., 2019), 1 evaluated allergenic potential of insect tropomyosin (Klueber et al., 2020), 3 studied the effects of food processing techniques on insects' allergenicity (Hall et al., 2018; Hall and Liceaga, 2020; Pali-Scholl et al., 2019), 4 were case reports or case series (Beaumont et al., 2019; Gadisseur et al., 2019; Nebbia et al., 2019; Sokol et al., 2017), 3 assessed the frequency of food allergies or food anaphylaxis caused by insects (Jiang et al., 2016; Lee et al., 2019; Rangkakulnuwat et al., 2020) and 2 assessed the prevalence of allergic reaction among insect-eaters (Chomchai et al., 2020; Taylor and Wang, 2018).

\section{Mechanisms of immunologic co-sensitisation or cross- reactivity with crustaceans}

In our previous review (Ribeiro et al., 2018), we pointed that immunologic co-sensitisation or cross-reactivity to edible insect species (such as mealworms, crickets, locusts and grasshoppers) had been shown for individuals allergic to crustaceans (or to crustaceans and HDM). The main allergens responsible for this cross-reactivity included arthropod pan-allergens tropomyosin and AK, although minor arthropod allergens (e.g. glyceraldehyde 3-phosphate dehydrogenase, myosin light chain, fructose-biphosphate aldolase, actin, $\alpha$-tubulin, $\beta$-tubulin or hexamerin) were also recognised as IgE-binding proteins. Additionally, a double-blind placebo controlled food challenge further confirmed the clinical significance of the cross-reactivity between crustaceans and Tenebrio molitor (Broekman et al., 2016).

Since then, immunologic co-sensitisation between edible insects and crustaceans was demonstrated for the first time for the following species: Galleria mellonella, Hermetia illucens (Broekman et al., 2017a), Acheta domesticus, Locusta migratoria (Broekman et al., 2017a; Pali-Scholl et al., 2019), Gryllodes sigillatus (Hall et al., 2018), and Schistocerca gregaria (Pali-Scholl et al., 2019). Moreover, new reports have re-confirmed immunologic co-sensitisation for T. molitor (Barre et al., 2019; Broekman et al., 2017a; Pali-Scholl et al., 2019), Zophobas morio, Alphitobius diaperinus (Broekman et al., 2017a) and Gryllus bimaculatus (Kamemura et al., 2019). Furthermore, functionality of the co-sensitisation in T. molitor was demonstrated through the application of BAT (Barre et al., 2019; Broekman et al., 2017a), while inhibition studies were used to confirm cross-reactivity with crustaceans (particularly shrimp) involving G. bimaculatus (Kamemura et al., 2019) and Sphenarium mexicanum (Sokol et al., 2017).

Concerning the allergens responsible for co-sensitisation or cross-reactivity, tropomyosin - whose role as an arthropod pan-allergen capable of causing cross-reactivity has been extensively reported (Wai et al., 2020; Wong et al., 2019) - has been identified as a cross-reacting allergen through immunoblotting in T. molitor (Barre et al., 2019; Klueber et al., 2020; Pali-Scholl et al., 2019), G. sigillatus (Hall et al., 2018), G. bimaculatus (Kamemura et al., 2019), S. mexicanum (Sokol et al., 2017), S. gregaria and A. domesticus (Pali-Scholl et al., 2019). Moreover, Kamemura et al. (2019), identified the high molecular 


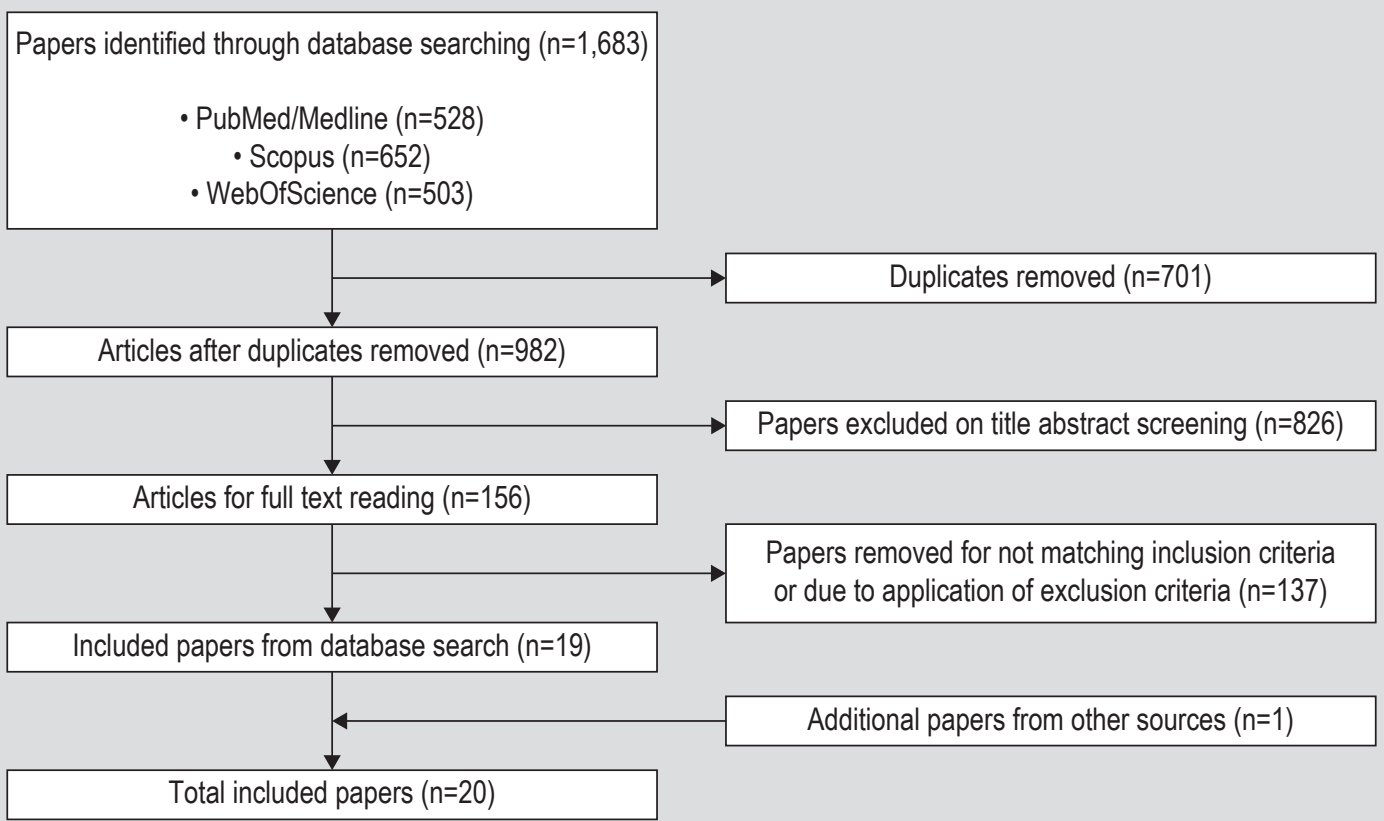

Figure 1. Flow chart of study selection process.

weight isoform of tropomyosin of G. bimaculatus as the antigen that induced shrimp-specific IgE, and it was additionally shown that this isoform had great sequence homology with both other insects species and shrimp tropomyosins. Nonetheless, there has been some conflicting information on T. molitor tropomyosin allergenicity - for example, Klueber et al. (2020) reported that this protein was capable of causing similar immunologic response (as measured by $\beta$-hexosaminidase release from rat basophilic leukaemia cells expressing the human high-affinity IgE receptor) to shrimp tropomyosin while Palmer et al. (2020) reported that in three mealworm species (T. molitor, G. mellonella and Z. morio) tropomyosin had lower IgE-reactivity than tropomyosin from A. domesticus or H. illucens. This variation in mealworm tropomyosin IgEreactivity may possibly be explained by individual patients characteristics, since Broekman et al. (2017a) reported that some shrimp-allergic patients had lower IgE-reactivity with mealworm tropomyosin than with tropomyosin from other insect species. Another possible explanation concerns small regionalised differences in protein sequence (most likely in IgE binding epitopes), since both the abundance of tropomyosin or overall sequence homology could not explain the verified diminished IgE-reactivity. Further research should be performed in order to assess if the molecular mechanisms of mealworm cross-reactivity are different from other insect species.

New studies have confirmed the role of other proteins which had been previously reported as involved in crossreactivity with crustaceans or HDM. Such proteins include heat shock protein 70, AK (Barre et al., 2019), and

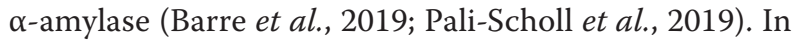
addition, larval cuticle protein, which has been identified as playing a major role in primary sensitisation to T. molitor (Broekman et al., 2017b), was also identified as a crossreacting protein (Barre et al., 2019). Furthermore, novel IgE-binding proteins have been identified. Such proteins were apolipophorin-III and $12 \mathrm{kDa}$ haemolymph protein, which have similar functions (binding and transport of hydrophobic ligands) (Barre et al., 2019). Apolipophorin has already been identified as a potential allergen in mealworms (Broekman et al., 2017a) due to its sequence homology with Der p 14, an allergen of HDM (Epton et al., 2001). Regarding the $12 \mathrm{kDa}$ haemolymph protein, it has been reported as one of the most abundant proteins in T. molitor supernatant (Yi et al., 2016), but its allergenicity had never been previously reported.

\section{Mechanisms of immunologic co-sensitisation or cross- reactivity with house dust mites}

In our previous review, we reported that only one study (Van Broekhoven et al., 2016) had used sera from patients solely allergic to HDM to assess cross-reactivity between edible insects and HDM. Sera from these patients was able to IgE-bind to extracts from mealworm species, and several cross-reacting proteins were identified (paramyosin, $\alpha$-amylase, actin, larval cuticle protein, hexamerin and myosin heavy chain). This suggests that the molecular mechanisms of cross-reactivity between edible insects and HDM are different from the ones regulating crossreactivity between crustaceans and HDM (with the latter being mostly related to tropomyosin) (Wong et al., 2016). 
Newly published studies have added additional insight into co-sensitisation between edible insects and HDM. The level of co-sensitisation to edible insects appears to be different in subjects only allergic to HDM when compared to those that are also allergic to crustaceans (or which are solely allergic to crustaceans). In fact, Barre et al. (2019) tested the sera of 13 HDM-allergic participants with T. molitor extracts, observing only 2 positive reactions. On the other hand, Pali-Scholl et al. (2019) reported that HDM-allergic patients had different patterns of IgE-reactivity to insects, which differed according to the tested species and body parts: there was no IgE-reactivity to $T$. molitor and to the bodies of $A$. domesticus, L. migratoria and S. gregaria; on the other hand, IgE-reactivity was found for the extremities (wings and legs) of the tested species.

Regarding allergens responsible for co-sensitisation, in a HDM-allergic patient that suffered food allergy to T. molitor, Beaumont et al. (2019) identified two allergens (tropomyosin and hexamerin 2A) by liquid chromatography coupled with tandem mass spectrometry (LC-MS/MS) while other cross-reacting proteins (larval cuticle proteins A1/A2, pupal cuticle protein G1A, $\alpha$-amylase and tubulin) were also possibly present (visible in 2D-Western Blot). Of these allergens, hexamerin, $\alpha$-amylase and larval cuticle protein had been previously identified as cross-reacting proteins between HDM and mealworm species (Van Broekhoven et al., 2016). Interestingly, hexamerin has also been described as a cross-reacting allergen between HDM and shellfish (Giuffrida et al., 2014). However, it is also important to note that, although tropomyosin was detected as a cross-reacting protein, such was based on the assessment of a subject which was not sensitised to shrimp or HDM tropomyosin, rendering unlikely that this allergen is responsible for cross-reactivity (Beaumont et al., 2019).

The scarcity of studies performed with HDM-only allergic patients hinders our knowledge concerning the allergens involved in this cross-reactivity and its clinical significance. Future research should be focused on HDM/edible insects cross-reactivity, especially considering the role that HDMsensitisation has on the development of shellfish allergy (Wai et al., 2020; Wong et al., 2016).

\section{Primary sensitisation}

Concerning primary sensitisation, in our previous review, we reported on studies which had been performed with individuals sensitised or with allergies to silkworm (Jeong et al., 2016; Liu et al., 2009; Wang et al., 2016; Zhao et al., 2015; Zuo et al., 2015). These studies have identified a wide array of IgE-binding elements, such as AK (Liu et al., 2009), chitinase (Zhao et al., 2015; Zuo et al., 2015), paramyosin (Zhao et al., 2015), 27-kDa heat-stable glycoprotein (Jeong et al., 2016), thiol peroxiredoxin (Wang et al., 2016), vitellogenin, $30 \mathrm{~K}$ protein, triosephosphate isomerase, heat shock protein and chymotrypsin inhibitor (Zuo et al., 2015). Of these, AK, paramyosin and chitinase were hypothesised to play a role in cross-reactivity with other arthropods (such as cockroaches or HDM), or even with shrimp due to their high sequence homology with known allergens of these species.

Newly published studies have focused on the detection and characterisation of allergens from $T$. molitor responsible for primary sensitisation and subsequent food allergy (Broekman et al., 2017b; Nebbia et al., 2019). Broekman et al. (2017b) identified larval cuticle proteins as major allergens of both respiratory and food allergy to T. molitor. On the other hand, Nebbia et al. (2019) hypothesised that cockroach allergen-like protein was the primary allergen in both respiratory and food allergies since it was present in extracts from $T$. molitor larvae and faeces (which authors proposed as the main route of sensitisation). These differences in the detected allergens could be explained by different routes of sensitisation, since the subjects reported by Nebbia et al. (2019) were mainly sensitised to T. molitor faeces while the subjects in the work by Broekman et al. (2017b) were not only domestic breeders of mealworm but also regular consumers of this insect. In addition, in both studies, arthropod pan-allergens such as tropomyosin, AK, myosin light and heavy chain (Broekman et al., 2017b), 86 $\mathrm{kDa}$ early-staged encapsulation protein, and troponin $\mathrm{C}$ (Nebbia et al., 2019) were detected as IgE-binding proteins.

However, it is still uncertain if primary sensitisation to edible insects can cause food allergies to crustaceans through cross-reactivity. In fact, Broekman et al. (2017b) observed that all subjects with primary sensitisation to T. molitor had negative oral challenges to shrimp, while the participants in the study by Nebbia et al. (2019) were not sensitised to shrimp or tropomyosin from other arthropods. Of note, Linares et al. (2008) had already previously described an individual with primary sensitisation and respiratory allergy to different species of crickets, but who had no detectable specific-IgE (sIgE) to allergic tropomyosins, and no crossreactivity for crustaceans or mites. This lack of tropomyosin IgE-reactivity was also demonstrated in subjects allergic to silkworm pupa (Jeong et al., 2017). These results seem to point out that tropomyosin might not play a major role in primary sensitisation to edible insects, which might explain the lack of cross-reactivity between individual primarily sensitised to edible insects and other arthropods. Nonetheless, it is known that there is a high degree of cosensitisation/cross-reactivity between cockroaches and shellfish, with tropomyosin playing a major role (Wai et al., 2020; Yang et al., 2018), although its clinical significance is not yet established (Wong et al., 2019)

Importantly, it is also possible that primary sensitisation can be somewhat species-specific, as observed in shrimp species (Jirapongsananuruk et al., 2008). In a study performed with 
four subjects who were primarily sensitised to $T$. molitor (with respiratory and/or food allergies), it was shown that subjects had variable reactivity and sensitisation to several insect species (Z. morio, A. diaperinus, G. mellonella, H. illucens, A. domesticus, L. migratoria) (Broekman et al., 2017a). Conversely, in the same study, most of shrimpallergic patients were co-sensitised to all the tested insect species. Interestingly, two subjects that have had an allergic reaction to $T$. molitor consumption reported no clinical symptoms after consuming other insect species (namely greater wax moths, black soldier flies and crickets) (Nebbia et al., 2019). However, some controversies remain on this question - in fact, Francis et al. (2019) reported that AK from T. molitor and from A. domesticus had weak conservation/homology, with apparent no cross reactivity between these species. On the contrary, Liu et al. (2009) not only identified AK as a major allergen of Bombyx mori, but also that it cross-reacts with AK from cockroaches.

\section{Effects of food processing technologies}

Some effects of food processing on edible insects' allergenicity had already been reported in our previous review. Overall, co-sensitisation between edible insects and crustaceans was reported not to be significantly diminished by thermal treatment (Broekman et al., 2015; Van Broekhoven et al., 2016), although the latter was described to have an impact on the intensity and types of allergens that are detected (Phiriyangkul et al., 2015). Furthermore, in vitro digestion had been shown not to eliminate IgE-binding capacity of mealworm tropomyosin (Van Broekhoven et al., 2016).

Food processing technologies are suggested to influence allergenicity of edible insects, and the effects of enzymatic hydrolysis (Hall et al., 2018; Pali-Scholl et al., 2019), microwave-assisted enzymatic hydrolysis (Hall and Liceaga, 2020), and heat treatment (Pali-Scholl et al., 2019) on edible insects allergenicity have been assessed. Hall et al. (2018) assessed the allergenicity behaviour of tropomyosin from cricket species G. sigillatus and found that only a degree of hydrolysis superior to $50 \%$ with alcalase ${ }^{\circledast}$ was able to eliminate its IgE-binding capacity to shrimp-allergic sera. In a follow-up work (Hall and Liceaga, 2020) with the same species, IgG-reactivity of tropomyosin was lower with microwave-assisted enzymatic hydrolysis (also performed with alcalase and a degree of hydrolysis greater than 50\%) than with just heat treatment (water bath or microwave) or water bath with enzymatic hydrolysis. These results are in line with previous studies, which had also suggested that insects' tropomyosin was able to maintain its allergenicity even after most thermal or enzymatic treatments (Broekman et al., 2015; Van Broekhoven et al., 2016). This behaviour is also present in shellfish tropomyosin, which has been described as resistant to most thermal treatments and even enzymatic hydrolysis (e.g. simulated gastric fluid and simulated intestinal fluid digestion systems) (Khan et al., 2019), although potentially susceptible to combinations of processing techniques (Mejrhit et al., 2017).

On the other hand, heat-treatment (water bath at 80 and $100{ }^{\circ} \mathrm{C}$ for 10 minutes or autoclaving at 121 and $138^{\circ} \mathrm{C}$ for 20 minutes) or enzymatic hydrolysis (flavourzyme, papain, alcalase, neutrase) eliminated IgE-reactivity to L. migratoria in whole protein extracts of subjects with allergy to both shrimp and HDM (Pali-Scholl et al., 2019). One possible explanation for these different results can be related to the protein extraction technique that was applied, which could have impacted the solubility and detection of the allergens, as shown in the work by Broekman et al. (2015).

\section{Prevalence of food allergy to insects}

The prevalence of allergic reactions caused by insect consumption has been assessed either through questionnaires directed to consumers of edible insects (Chomchai et al., 2020; Taylor and Wang, 2018) (Table 1) or through retrospective analyses of series of patients assessed for food allergy or for anaphylaxis (Jiang et al., 2016; Lee et al., 2019; Rangkakulnuwat et al., 2020) (Table 2).

Two studies assessed the prevalence of allergic reactions among consumers of edible insects. Such studies were performed in Thailand, and relied on self-reported symptoms following the consumption of insects. Chomchai et al. (2020) performed an Internet survey, where it was observed that 18 out of 140 assessed subjects (12.9\%; 95\% confidence interval $[\mathrm{CI}]=7.3-18.5 \%)$ reported allergic reactions following the consumption of insects, of whom 4 (22.2\%; 95\%CI=3.0-41.4\%) reported severe symptoms. Furthermore, the occurrence of an allergic reaction to insects was found to be associated with a history of other allergies, including food allergy to seafood. Taylor and Wang (2018) assessed the characteristics of insect-consumers in the North-Eastern region of Thailand through a crosssectional survey delivered in public schools and hospitals, and reported that $14.7 \%(95 \% \mathrm{CI}=13.1-16.3 \%$; 288 of 1,956$)$ of insect consumers reported the occurrence of a single symptom after consuming insects, and 7.4\% (95\%CI $=6.2$ $8.6 \% ; 146 / 1,956)$ reported multiple symptoms. Furthermore, $72.3 \%$ (95\%CI=61.4-83.2\%; 47/65) of those reporting preexisting food allergies, reported at least a single symptom following the consumption of insects. Severe reactions had allegedly been experienced by 150 participants (7.6\%, 95\%CI=6.3-8.7\%; 150/1,956); however, the study does not clearly specify how such reactions were defined.

A previous study performed in Laos had reported lower frequencies of allergic reactions $(81 / 1,059 ; 7.6 \% 95 \% \mathrm{CI}=6.0$ 9.2\%) (Barennes et al. (2015) (Supplementary Table S1). These differences reflect not only different consumption habits, but also different sampling methods - while 
Table 1. Description of studies assessing prevalence of food allergy amongst consumers of edible insects.

\begin{tabular}{|c|c|c|c|c|c|c|}
\hline Reference/Study & Country & Methodology & $\begin{array}{l}\text { Total } \\
\text { number of } \\
\text { subjects }-\mathrm{n}\end{array}$ & $\begin{array}{l}\text { Number of self- } \\
\text { reported allergic } \\
\text { reactions - } \mathrm{n} \\
(\% ; 95 \% \mathrm{Cl})\end{array}$ & $\begin{array}{l}\text { Species } \\
\text { (number of cases) }\end{array}$ & Other information \\
\hline $\begin{array}{l}\text { Taylor and Wang } \\
\text { (2018) }\end{array}$ & Thailand & $\begin{array}{l}\text { cross-sectional survey } \\
\text { assessing, amongst } \\
\text { others, the occurrence } \\
\text { of side effects after } \\
\text { eating insects }\end{array}$ & 1,956 & $\begin{array}{l}434(22.2 \% \\
20.4-24.0 \%)\end{array}$ & $\begin{array}{l}\text { water bugs }-42.9 \% \\
\text { scorpions }-30.0 \% \\
\text { grasshoppers }-22.3 \% \\
\text { crickets }-21.6 \% \\
\text { bamboo worms }-17.1 \% \\
\text { red ants }-17.0 \% \\
\text { silkworms }-16.7 \% \\
\text { red ant eggs }-11.4 \%\end{array}$ & $\begin{array}{l}14.7 \%(95 \% \mathrm{Cl}=13.1-16.3 \% \text {; } \\
288 / 1956) \text { reported the } \\
\text { occurrence of a single } \\
\text { symptom and } 7.4 \% \\
(95 \% \mathrm{Cl}=6.2-8.6 \% ; \\
146 / 1956) \text { reported } \\
\text { multiple symptoms; } 72.3 \% \\
(95 \% \mathrm{Cl}=61.4-83.2 \% ; \\
47 / 65) \text { of those reporting } \\
\text { pre-existing food allergies, } \\
\text { reported at least a single } \\
\text { symptom following the } \\
\text { consumption of insects }\end{array}$ \\
\hline $\begin{array}{l}\text { Chomchai et al. } \\
(2020)\end{array}$ & Thailand & $\begin{array}{l}\text { internet-based cross- } \\
\text { sectional survey of } \\
\text { people who practiced } \\
\text { entomophagy }\end{array}$ & 140 & $\begin{array}{l}18(12.9 \% ; 7.3- \\
18.5 \%)\end{array}$ & $\begin{array}{l}\text { silkworm larva } \\
\quad(8-44.4 \%) \\
\text { grasshopper }(4-22.2 \%) \\
\text { cricket }(3-16.7 \%) \\
\text { bamboo caterpillar } \\
\quad(3-16.7 \%)\end{array}$ & $\begin{array}{l}\text { allergic symptoms after } \\
\text { insect consumption were } \\
\text { associated with a history } \\
\text { of respiratory allergy, skin } \\
\text { allergy and seafood allergy }\end{array}$ \\
\hline
\end{tabular}

Table 2. Description of studies which retrospectively analysed food allergic reactions, and which included cases caused by insects.

\begin{tabular}{|c|c|c|c|c|c|c|}
\hline Reference & Country & Methodology & $\begin{array}{l}\text { Total number of } \\
\text { cases of food } \\
\text { anaphylaxis/ } \\
\text { allergy }\end{array}$ & $\begin{array}{l}\text { Number of } \\
\text { cases caused } \\
\text { by insects - } \\
n(\% ; 95 \% \mathrm{Cl})\end{array}$ & $\begin{array}{l}\text { Species } \\
\text { (number of cases) }\end{array}$ & $\begin{array}{l}\text { Other } \\
\text { information }\end{array}$ \\
\hline Jiang et al. (2016) & China & $\begin{array}{l}\text { retrospective review of outpatients } \\
\text { diagnosed with 'anaphylaxis' or 'severe } \\
\text { allergic reactions' in the Department of } \\
\text { Allergy, Peking Union Medical College } \\
\text { Hospital, from January } 2000 \text { to June } 2014\end{array}$ & 1,501 & $\begin{array}{l}5(0.3 \% \\
0.02-0.6 \%)\end{array}$ & $\begin{array}{l}\text { locusts (2) } \\
\text { cicada (2) } \\
\text { silkworm chrysalis } \\
\text { (1) }\end{array}$ & \\
\hline Lee et al. (2019) & Korea & $\begin{array}{l}\text { retrospective review of the medical } \\
\text { records of } 812 \text { Korean adult patients with } \\
\text { suspected food allergy and who visited } \\
\text { the Allergy Asthma Centre of a tertiary } \\
\text { hospital in Korea from January } 2014 \text { to } \\
\text { December } 2018\end{array}$ & 415 & $\begin{array}{l}13(3.1 \% \\
1.4-4.8 \%)\end{array}$ & silkworm pupa (13 & $\begin{array}{l}46.2 \%(6 / 13 ; \\
95 \% \mathrm{Cl}= \\
19.1-73.3 \%) \\
\text { also had food } \\
\text { allergy to } \\
\text { shellfish }\end{array}$ \\
\hline $\begin{array}{l}\text { Rangkakulnuwat } \\
\text { et al. (2020) }\end{array}$ & Thailand & $\begin{array}{l}\text { retrospective review of electronic medical } \\
\text { records of patients who attended the } \\
\text { outpatient and emergency departments } \\
\text { at Chiang Mai University Hospital from } \\
\text { January } 2007 \text { to December } 2016\end{array}$ & 209 & $\begin{array}{l}17(8.1 \% \\
\quad 4.4-11.8 \%)\end{array}$ & $\begin{array}{l}\text { fried insects, } \\
\text { namely } \\
\text { grasshopper, } \\
\text { crickets, silk worms, } \\
\text { and bamboo worms } \\
\text { (n not specified) }\end{array}$ & \\
\hline
\end{tabular}


Barennes et al. (2015) and Taylor and Wang (2018) performed their studies on populations where entomophagy is common, Chomchai et al. (2020) recruited participants through posters and ads in websites which could mean that people who suffered allergic reactions were more predisposed to participate in the survey. Furthermore, all these studies assessed self-reported reactions, which can also lead to an overestimation of food allergy cases. For instance, in the study performed by Taylor and Wang (2018), many of the cases classified as food allergy could be instead cases of food poisoning or allergic reaction to poison, since water bugs (Lethocerus indicus) (which are mostly eaten without cooking) and scorpions (Heterometrus longimanus) were the species that were reported to cause most allergic reactions, despite being two of the least consumed species by the participants. In fact, food poisoning - which is out of scope of this review - due to insect consumption is not rare, with several described reports of outbreaks of histamine poisoning (Chomchai and Chomchai, 2018). Histamine poisoning, also designed scombroid poisoning, is a foodborne illness that occurs due to toxic levels of histamine (caused by histidine decarboxylase formed by histamine-producing bacteria) mainly in spoiled fish and whose symptoms are very similar to IgE-mediated food allergy (Wu et al., 1997).

Concerning the retrospective analyses of cases of food allergy or anaphylaxis, three different studies (Jiang et al., 2016; Lee et al., 2019; Rangkakulnuwat et al., 2020) have been performed in Asia. Lee et al. (2019) retrospectively analysed medical records of 415 adult patients with suspected food allergy, reporting that 13 confirmed cases (3.1\%; 95\%CI=1.4-4.8\%) were caused by consumption of silkworm pupae. Additionally, six of those 13 patients (46.2\%; 95\%CI $=19.1-73.3 \%)$ also had food allergy to shellfish. The other studies (Jiang et al., 2016; Rangkakulnuwat et al., 2020) have focused on retrospective analysis of cases of food anaphylaxis and found that insect consumption caused 0.3\% (5/1,501; 95\%CI=0.02-0.6\%) (Jiang et al., 2016) and $8.1 \%(17 / 209 ; 95 \% \mathrm{CI}=4.4-11.8 \%)$ (Rangkakulnuwat et al., 2020) of food anaphylaxis cases. Previous studies (Supplementary Table S2) have reported widely different values of food anaphylaxis caused by the consumption of insects $-5.2 \%(1 / 24 ; 95 \% \mathrm{CI}=0.0-12.2 \%)$ (Jirapongsananuruk et al., 2007), $17.6 \%(63 / 358 ; 95 \% \mathrm{CI}=13.6-21.4 \%)$ (Ji et al., 2009), and $19.4 \%(7 / 36 ; 95 \% \mathrm{CI}=6.5-32-3 \%)$ (Piromrat et al., 2008). These differences in values and in the species causing most reactions can mirror the consumption habits of the regions where the studies were performed. Nonetheless, it is noteworthy to mention that there are studies assessing the prevalence of food allergy in Asia and that do not mention insects as causative agents of food allergy (Le et al., 2019; Lee et al., 2013). This can happen because entomophagy is a more common practice in specific regions and rural areas (Manditsera et al., 2018) which can lead to several cases going unreported at national levels.

\section{Case reports and case series}

In our previous review, we were able to retrieve 29 cases reports of food allergies caused by insects' consumption (Supplementary Table S3). Most of the cases occurred in Asia and Africa, with the causative species mostly reflecting regional consumption habits. For example, the reported reactions that occurred in China (Ji et al., 2008) were due to silkworm pupae, while the reactions occurring in Botswana were caused by mopane worms (Kung et al., 2011, 2013; Okezie et al., 2010). In most cases (18/29), the reactions occurred after consuming the insect for the first time, suggesting that these reactions could have occurred due to cross-reactivity with crustaceans or HDM. In fact, two of the subjects had previous history of allergic reactions to shellfish (Choi et al., 2010; Piatt, 2005), while other nine had subjects were either sensitised to common aeroallergens or had an history of allergic diseases (Broekman et al., 2017b; Choi et al., 2010; Freye, 1996; Ji et al., 2008; Kung et al., 2011, 2013). Furthermore, in three cases (Broekman et al., 2017b; Freye, 1996) the mechanism for food allergy was probably primary sensitisation since it occurred in subjects which were constantly exposed to the species.

In this review, we identified 16 new cases of food allergy caused by the consumption of insects (Table 3; Beaumont et al., 2019; Gadisseur et al., 2019; Nebbia et al., 2019; Sokol et al., 2017). These cases occurred in France (Beaumont et al., 2019), United States of America (Sokol et al., 2017), Italy (Nebbia et al., 2019) and Niger (Gadisseur et al., 2019). The species that caused the allergic reactions were chapulines (S. mexicanum) (Sokol et al., 2017), T. molitor (Beaumont et al., 2019; Nebbia et al., 2019), and crickets (Gadisseur et al., 2019).

The five cases that occurred in Western countries (Beaumont et al., 2019; Nebbia et al., 2019; Sokol et al., 2017) represent three of the different pathways involved in food allergy to edible insects: cross-reactivity with crustaceans/HDM (Sokol et al., 2017), cross-reactivity with HDM (Beaumont et al., 2019), and primary sensitisation (Nebbia et al., 2019). The two patients in the cases reported by Sokol et al. (2017) had previous history of food allergy to shellfish while also being sensitised to common aeroallergens (including HDM). The patient in the case reported by Beaumont et al. (2019) only had previous history of respiratory allergy to HDM and was not sensitised to shrimp. Furthermore, in these three cases, the allergic reactions occurred after consuming the insect species for the first time, as observed in most of the previously reported cases (Ribeiro et al., 2018). This further suggests that these reactions occurred through cross-reactivity to HDM and/or crustaceans.

Additionally, two of the reported cases (Nebbia et al., 2019) occurred due to primary sensitisation to the causative species (T. molitor larvae). These two cases are very similar 
Table 3. Description of reported cases of allergy to insects' consumption. ${ }^{1,2}$

\begin{tabular}{|c|c|c|c|c|c|}
\hline Reference & $\begin{array}{l}\text { Age/sex/ } \\
\text { nationality }\end{array}$ & Species & $\begin{array}{l}\text { Clinical } \\
\text { symptoms }\end{array}$ & Clinical history of allergies & Other characteristics \\
\hline $\begin{array}{l}\text { Sokol et al. } \\
(2017)\end{array}$ & 43/M/American & $\begin{array}{l}\text { Chapulines } \\
\text { (Sphenarium } \\
\text { mexicanum) }\end{array}$ & $\begin{array}{l}\text { I, S (lips and } \\
\text { tongue), UC, } \\
\text { AP, D }\end{array}$ & $\begin{array}{l}\text { history of allergic } \\
\text { rhinoconjunctivitis, bronchial } \\
\text { asthma and food allergy to } \\
\text { shellfish }\end{array}$ & $\begin{array}{l}\text { Reaction occurred after consuming chapulines for } \\
\text { the first time } \\
\text { Positive SPT and slgE to grasshopper, chapulines, } \\
\text { crickets, cockroach, mites, shellfish, cat and dog } \\
\text { slgE inhibition with chapulines to grasshopper, } \\
\text { crickets, cockroach, mites, shellfish } \\
\text { Identification of tropomyosin in immunoblot }\end{array}$ \\
\hline $\begin{array}{l}\text { Sokol et al. } \\
(2017)\end{array}$ & 50/F/American & $\begin{array}{l}\text { Chapulines } \\
\text { (S. mexicanum) }\end{array}$ & $\begin{array}{l}\text { I (mouth, throat, } \\
\text { generalised), } \\
\text { S (face, lips, } \\
\text { perioral tissue, } \\
\text { throat), DSw, } \\
\text { DSp, Sy }\end{array}$ & $\begin{array}{l}\text { history of allergic } \\
\text { rhinoconjunctivitis, bronchial } \\
\text { asthma, intermittent urticaria, } \\
\text { moderately severe atopic } \\
\text { dermatitis and food allergy to } \\
\text { shellfish }\end{array}$ & $\begin{array}{l}\text { Reaction occurred after consuming chapulines for } \\
\text { the first time } \\
\text { Positive SPT and slgE to grasshopper, chapulines, } \\
\text { crickets, cockroach, mites, shellfish, cat and dog } \\
\text { slgE inhibition with chapulines to grasshopper, } \\
\text { crickets, cockroach and shellfish } \\
\text { Identification of tropomyosin in Immunoblot }\end{array}$ \\
\hline $\begin{array}{l}\text { Beaumont } \\
\text { et al. (2019) }\end{array}$ & 31/M/French & $\begin{array}{l}\text { Yellow } \\
\text { mealworm } \\
\text { (Tenebrio } \\
\text { molitor) }\end{array}$ & U, A, Dys, N & rhinitis and mild asthma & $\begin{array}{l}\text { Positive SPT and slgE to dust mites and mealworm } \\
\text { Positive slgE to Der } p 1 \text {, Der } p 2 \text { and Der } p 23 \text {. } \\
\text { Negative slgE to Pen a } 1 \text { and Der } p 10 \\
\text { Identification of IgE-binding proteins: tubulin } \\
\text { a-chain, } a \text {-amylase, tropomyosin, hexamerin, } \\
\text { pupal cuticle protein G1A and larval cuticle } \\
\text { protein }\end{array}$ \\
\hline $\begin{array}{l}\text { Nebbia et al. } \\
(2019)\end{array}$ & 24/M/Italian & $\begin{array}{l}\text { Yellow } \\
\text { mealworm } \\
\text { (T. molitor) }\end{array}$ & $\begin{array}{l}\mathrm{OAS}-\mathrm{P} \text { (oral), } \\
\mathrm{T} \text { (throat) }\end{array}$ & $\begin{array}{l}\text { rhinoconjunctivitis, itching } \\
\text { and contact erythema when } \\
\text { exposed to T. molitor }\end{array}$ & $\begin{array}{l}\text { Consumed other species (greater wax moth, } \\
\text { black soldier fly and crickets) without developing } \\
\text { allergic reactions } \\
\text { Reaction occurred after T. molitor hamburger for } \\
\text { the first time } \\
\text { Positive SPT to grass } \\
\text { Positive SPT and BAT to T. molitor } \\
\text { Identification of cockroach allergen-like } \\
\text { protein, Troponin C and } 86 \mathrm{kDa} \text { early-staged } \\
\text { encapsulation protein as IgE-binding proteins }\end{array}$ \\
\hline $\begin{array}{l}\text { Nebbia et al. } \\
(2019)\end{array}$ & 27/M/Italian & $\begin{array}{l}\text { Yellow } \\
\text { mealworm } \\
\text { (T. molitor) }\end{array}$ & $\begin{array}{l}\text { OAS, } \mathrm{P} \text { (oral), } \\
\mathrm{T} \text { (throat) }\end{array}$ & $\begin{array}{l}\text { rhinoconjunctivitis, itching } \\
\text { and contact erythema when } \\
\text { exposed to T. molitor }\end{array}$ & $\begin{array}{l}\text { Consumed other species (greater wax moth, } \\
\text { black soldier fly and crickets) without developing } \\
\text { allergic reactions } \\
\text { Reaction occurred after T. molitor hamburger for } \\
\text { the first time } \\
\text { Positive SPT to Alternaria } \\
\text { Positive SPT and BAT to T. molitor } \\
\text { Identification of cockroach allergen-like } \\
\text { protein, Troponin C and } 86 \mathrm{kDa} \text { early-staged } \\
\text { encapsulation protein as IgE-binding proteins }\end{array}$ \\
\hline $\begin{array}{l}\text { Gadisseur } \\
\text { et al. (2019) }\end{array}$ & 31/M/Nigerien & Crickets & $\begin{array}{l}\text { OAS, U, A, } \\
\text { GI, V }\end{array}$ & allergy to shrimp and HDM & $\begin{array}{l}\text { Sensitised (positive SPT and/or slgE) to shrimp, } \\
\text { HDM, cockroach and cricket. } \\
\text { Positive slgE to HDM allergens (Der } p \text { 1, Der } p \text { 2, } \\
\text { Der f 1, Der } f \text { 2) }\end{array}$ \\
\hline
\end{tabular}


Table 3. Continued.

\begin{tabular}{|c|c|c|c|c|c|}
\hline Reference & $\begin{array}{l}\text { Age/sex/ } \\
\text { nationality }\end{array}$ & Species & $\begin{array}{l}\text { Clinical } \\
\text { symptoms }\end{array}$ & Clinical history of allergies & Other characteristics \\
\hline $\begin{array}{l}\text { Gadisseur et } \\
\text { al. (2019) }\end{array}$ & 26/F/Nigerien & Crickets & $\begin{array}{l}\text { OAS, Dys, } \\
\text { HT, V, A }\end{array}$ & allergy to shrimp & $\begin{array}{l}\text { Sensitised (positive SPT and/or slgE) to shrimp } \\
\text { and cricket } \\
\text { Positive slgE to Der } p 10 \text { (HDM tropomyosin), } \\
\text { Pen a 1, Pen m } 1 \text { (shrimp tropomyosin), Bla g } 7 \\
\text { (cockroach tropomyosins) and HDM allergens } \\
\text { (Der } p 1 \text {, Der } p 2 \text {, Der } f \text { 1, Der } f \text { 2) }\end{array}$ \\
\hline $\begin{array}{l}\text { Gadisseur et } \\
\text { al. (2019) }\end{array}$ & 26/F/Nigerien & Crickets & $\begin{array}{l}\text { OAS, U, A, } \\
R, C, G I\end{array}$ & $\begin{array}{l}\text { allergy to shrimp and } \\
\text { cockroach }\end{array}$ & $\begin{array}{l}\text { Sensitised (positive SPT and/or slgE) to shrimp, } \\
\text { cockroach and cricket } \\
\text { Positive slgE to Der } \mathrm{p} 10 \text { (HDM tropomyosin) } \\
\text { Pen a 1, Pen m } 1 \text { (shrimp tropomyosin), Bla g } 7 \\
\text { (cockroach tropomyosins), Pen m } 2 \text { (shrimp AK) }\end{array}$ \\
\hline $\begin{array}{l}\text { Gadisseur et } \\
\text { al. (2019) }\end{array}$ & 36/M/Nigerien & Crickets & OAS, U, A & allergy to shrimp & $\begin{array}{l}\text { Sensitised (positive SPT and/or slgE) to cockroach } \\
\text { and cricket }\end{array}$ \\
\hline $\begin{array}{l}\text { Gadisseur et } \\
\text { al. (2019) }\end{array}$ & 44/M/Nigerien & Crickets & U, OAS, GI, V & allergy to shrimp & $\begin{array}{l}\text { Sensitised (positive SPT and/or slgE) to shrimp, } \\
\text { cockroach and cricket }\end{array}$ \\
\hline $\begin{array}{l}\text { Gadisseur et } \\
\text { al. (2019) }\end{array}$ & 55/F/Nigerien & Crickets & OAS, U & $\begin{array}{l}\text { no previous history of } \\
\text { allergies }\end{array}$ & $\begin{array}{l}\text { Sensitised (positive SPT and/or slgE) to shrimp, } \\
\text { HDM, cockroach and cricket } \\
\text { Positive slgE to Der } p 10 \text { (HDM tropomyosin), Pen } \\
\text { a } 1 \text { (shrimp tropomyosin) and Pen m } 2 \text { (shrimp } \\
\text { AK) }\end{array}$ \\
\hline $\begin{array}{l}\text { Gadisseur et } \\
\text { al. (2019) }\end{array}$ & 39/M/Nigerien & Crickets & U, GI, V & $\begin{array}{l}\text { allergy to shrimp and } \\
\text { cockroach }\end{array}$ & $\begin{array}{l}\text { Sensitised (positive SPT and/or slgE) to shrimp, } \\
\text { cockroach and cricket } \\
\text { Positive slgE Pen a 1, Pen m } 1 \text { (shrimp } \\
\text { tropomyosin), Pen m } 2 \text { (shrimp AK) and Pen m } 4 \\
\text { (shrimp Sarcoplasmic Calcium-Binding Protein) }\end{array}$ \\
\hline $\begin{array}{l}\text { Gadisseur et } \\
\text { al. (2019) }\end{array}$ & 8/F/Nigerien & Crickets & OAS, U & allergy to cockroach & $\begin{array}{l}\text { Sensitised (positive SPT and/or slgE) to shrimp, } \\
\text { cockroach and cricket } \\
\text { Positive slgE to Pen m } 2 \text { (shrimp AK) }\end{array}$ \\
\hline $\begin{array}{l}\text { Gadisseur et } \\
\text { al. (2019) }\end{array}$ & 20/M/Nigerien & Crickets & $U$ & allergy to HDM & $\begin{array}{l}\text { Sensitised (positive SPT and/or slgE) to shrimp, } \\
\text { HDM, cockroach and cricket } \\
\text { Positive slgE to HDM allergens (Der p 1, Der p 2, } \\
\text { Der f 1, Der f } 2 \text { ) and Pen m } 2 \text { (shrimp AK) }\end{array}$ \\
\hline $\begin{array}{l}\text { Gadisseur et } \\
\text { al. (2019) }\end{array}$ & 14/F/Nigerien & Crickets & $\mathrm{Gl}$ & allergy to cockroach & $\begin{array}{l}\text { Sensitised (positive SPT and/or slgE) to shrimp, } \\
\text { cockroach and cricket } \\
\text { Positive slgE to Bla g } 1\end{array}$ \\
\hline $\begin{array}{l}\text { Gadisseur et } \\
\text { al. (2019) }\end{array}$ & 31/M/Nigerien & Crickets & OAS & allergy to shrimp & $\begin{array}{l}\text { Positive SPT to dust mites and mopane worm } \\
\text { Positive slgE to Der p } 10 \text { (HDM tropomyosin), } \\
\text { Pen a } 1 \text { (shrimp tropomyosin), Pen m } 2 \text { (shrimp } \\
\text { AK) and Bla g } 5 \text { (cockroach Glutathione } \\
\text { S-transferase) }\end{array}$ \\
\hline
\end{tabular}

${ }^{1}$ Clinical symptoms: $\mathrm{A}=$ angioedema; $\mathrm{AP}=$ abdominal pain; $\mathrm{BAT}=$ Basophil Activation Test $\mathrm{C}=$ conjunctivitis; $\mathrm{D}=$ diarrhoea; $\mathrm{DSp}=$ difficulty speaking; $\mathrm{DSw}=$ difficulty swallowing; Dys = dyspnoea; $\mathrm{GI}$ = gastrointestinal trouble; $\mathrm{HT}$ = hypotension; $\mathrm{I}$ = itchiness; $\mathrm{N}=$ nausea; $\mathrm{OAS}=$ oral allergy syndrome; $\mathrm{P}=$ pruritus; $\mathrm{R}=$ rhinitis; $\mathrm{S}=$ swelling; $\operatorname{slg} \mathrm{E}=$ Specific $\lg \mathrm{E} ; \mathrm{SPT}=$ skin prick test; $\mathrm{Sy}=$ syncope; $\mathrm{T}$ = tightness; $\mathrm{U}=$ urticaria; $\mathrm{UC}=$ unconsciousness; $\mathrm{V}=$ vomiting

${ }^{2}$ List of allergens (WHO/IUIS, 2020): Der $p 1$ = cysteine protease from the European house dust mite Dermatophagoides pteronyssinus; Der $\mathrm{p} 2=$ Niemann-Pick proteins of class C2 family from Dermatophagoides pteronyssinus; Der p $10=$ tropomyosin from Dermatophagoides pteronyssinus; Der p23 = peritrophin-like protein domain (PF01607) from Dermatophagoides pteronyssinus; Der $\mathrm{f} 1$ = cysteine protease from the American house dust mite Dermatophagoides farinae; Der $\mathrm{f} 2$ = Niemann-Pick proteins of class C2 from Dermatophagoides farinae; Pen a 1 = tropomyosin from brown shrimp Penaeus aztecus; Pen $\mathrm{m} 1$ = tropomyosin from the black tiger shrimp Penaeus monodon; Pen $\mathrm{m} 2$ = arginine kinase from Penaeus monodon; Pen $\mathrm{m} 4$ =Sarcoplasmic calcium binding protein from Penaeus monodon; Bla g 1 = microvilli-like protein with unknown function from the German cockroach Blattella germanica; Bla g 7 = tropomyosin from Blattella germanica. 
to two other previously reported by Broekman et al. (2017b), since the patients were constantly exposed to T. molitor on their work and had no previous history of food allergy to shellfish or sensitisation to shrimp. Additionally, in both cases reported by Nebbia et al. (2019), the subjects also had respiratory allergies to T. molitor, while in the report by Broekman et al. (2017b) only one subject developed, respiratory allergies although he had previous history of allergies caused by HDM.

Furthermore, Gadisseur et al. (2019) assessed the sensitisation profile of a entomophagous population in Niger who displayed symptoms of allergy to insects and/or crustaceans/HDM. This study described 11 subjects with cases of food allergy following the consumption of crickets. In most cases (10 of 11), subjects had previous history of allergic diseases with the most common being food allergy to shellfish $(7 / 11 ; 64 \%)$. Regarding sensitisation to allergens, sIgE to tropomyosin was detected in 5 individuals $(5 / 11 ; 45 \%)$, while sIgE to AK was detected in $6(6 / 11 ; 55 \%)$ subjects, respectively. It is also noteworthy to mention that, in the same study, 3 subjects who consumed crickets without developing any symptoms of food allergy were all sensitised to crickets, shrimp and cockroach. Additionally, in these subjects, sIgE was only detected for Bla g 1 (cockroach nitrile specifier), Der p 1 (mite Dermatophagoides pteronyssinus cysteine protease) and Der 1 (mite Dermatophagoides farinae cysteine protease). These cases illustrate that sensitisation (such as positive skin prick test or sIgE to common arthropod allergens) alone is not an indication that a clinical reaction can happen.

Providing contextual information about cases of food allergy to insects' consumption is essential to better understand the mechanisms that regulate those reactions. In our previous review (Ribeiro et al., 2018), lack of contextual information hindered our analysis of reported cases and only 12 of 29 individuals with food allergies to insects (41\%) had previous allergic diseases or were primarily sensitised to the culprit species. On the other hand, in cases reviewed in this work, these situations occurred in 15 of 16 individuals (94\%). Current literature of reported cases highlights that individual allergic to crustaceans or that are constantly exposed to edible insects appear to be the two major group risks for developing food allergies to insects. Nonetheless, several cases occurred in individuals which were sensitised to HDM or had history of allergic diseases (e.g. allergic rhinitis) which emphasises that individuals allergic to HDM may also be a risk group of food allergies to insects.

\section{Conclusions}

In conclusion, the current literature points that the two major risk groups for development of food allergy to insects' consumption are subjects allergic to crustaceans and individuals constantly exposed to edible insects. For subjects allergic to crustaceans, reactions to edible insects may occur due to cross-reactivity, which seems to be mainly mediated through tropomyosin, with tropomyosin from T. molitor being able to produce an allergic response in an animal model. However, other minor allergens (e.g. AK and $\alpha$-amylase) may also play a role and previously unreported IgE-binding proteins (apolipophorin and $12 \mathrm{kDa}$ haemolymph protein) were identified. The allergenicity of edible insects seems to be resistant to thermal treatments and digestion with enzymes (unless very specific conditions are applied), a similar behaviour to crustaceans' allergens.

On the other hand, it has also been demonstrated that individuals constantly exposed to T. molitor can become sensitised and subsequently develop a food allergy to this insect. Different allergens (larval cuticle protein and cockroach allergen-like protein) were identified depending on the route of sensitisation. Significantly, tropomyosin has not been identified as a significant allergen in primary sensitisation to T. molitor or silkworm. Additionally, it is still uncertain if this sensitisation is species-specific or if it can lead to co-sensitisation with other insect species or crustaceans.

On the other hand, co-sensitisation has been shown between HDM and edible insects, but it seems to be different from co-sensitisation between edible insects and crustaceans - a relatively small number of HDM-allergic patients are sensitised to edible insects, and IgE-binding to edible insects only occurs in specific body parts. Additionally, the clinical relevance of such co-sensitisation is not yet defined, and the underlying molecular mechanisms remain unclear (although hexamerin has been consistently identified in all studies), especially considering the apparent lack of involvement of tropomyosin.

Although substantial work has been performed within the topic of edible insects' allergenicity, there are still gaps in our current knowledge. Concerning cross-reactivity with crustaceans, future studies should assess the allergenicity of other species besides T. molitor, and a comparison of the molecular mechanisms between different species should be performed, namely by using extracts from different species and serum from the same patients. One of the focal points of future research should be performing studies with individuals monosensitised to HDM in order to have a better understating of HDM-edible insects cross-reactivity. The clinical significance of this co-sensitisation is still unclear and biological assays (preferably food challenges) should be performed.

One of the major flaws when studying food allergy to edible insects is the lack of reliable epidemiological data, since there still is a lack of reported cases/series of food allergy to edible insects. Prevalence studies performed in Asian countries have reported that $0.3-19.4 \%$ of food anaphylaxis/ 
allergy cases were caused by insects' consumption. Furthermore, studies performed with populations of insect-eaters haver reported that 7.6-22.2\% of individuals suffered allergic reactions after consuming insects (although these rates could be overestimated because they were bases on selfreported reactions). Despite these high prevalences, we were only able to retrieve a total of 45 cases in both reviews. This can happen because the regions where insects are consumed are mostly rural (possibly leading to sub-notification), or because several cases may have only been published in local literature (e.g. Chinese). Given the large pool of subjects allergic to the consumption of insects in these areas, it is of extreme importance for these cases to be reported so that we can better understand the characteristics of food allergy to insects, including their severity and epidemiological association with other allergy diseases. In fact, it is expected that an increasing number of cases of food allergy will be reported, due to the introduction of edible insects in the food market of Western countries. This impact is already evident, as food allergy cases have already been reported in subjects who work with T. molitor (Broekman et al., 2017b; Nebbia et al., 2019), although the number of reported cases (4) is still very small. These types of cases are essential to have a better understanding of primary sensitisation to edible insects, namely regarding the major allergens involved and whether such sensitisation is species-specific.

\section{Acknowledgements}

Author J.C. Ribeiro acknowledges Doctoral grant No. SFRH/BD/147409/2019 funded by Fundação para a Ciência e a Tecnologia (FCT). Authors J.C. Ribeiro, S.C. Fonseca and L.M. Cunha acknowledge financial support from the national funds by FCT within the scope of UIDB/05748/2020 and UIDP/05748/2020.

\section{Conflict of interest}

The authors declare no conflict of interest.

\section{Supplementary material}

Supplementary material can be found online at https://doi. org/10.3920/JIFF2020.0065.

Table S1. Description of studies assessing prevalence of food allergy amongst consumers of edible insects, included in both systematic reviews (current article and Ribeiro et al. 2018).

Table S2. Description of studies included in both systematic reviews (current article and Ribeiro et al. 2018), which retrospectively analysed food allergic reaction, including cases caused by insects.
Table S3. Description of reported cases included in both systematic reviews (current article and Ribeiro et al. 2018) of allergy to insects' consumption.

\section{References}

Barennes, H., Phimmasane, M. and Rajaonarivo, C., 2015. Insect consumption to address undernutrition, a national survey on the prevalence of insect consumption among adults and vendors in Laos. PLoS One 10: e0136458. https://doi.org/10.1371/journal. pone. 0136458

Barre, A., Pichereaux, C., Velazquez, E., Maudouit, A., Simplicien, M., Garnier, L., Bienvenu, F., Bienvenu, J., Burlet-Schiltz, O., Auriol, C., Benoist, H. and Rouge, P., 2019. Insights into the allergenic potential of the edible yellow mealworm (Tenebrio molitor). Foods 8: 515. https://doi.org/10.3390/foods8100515

Beaumont, P., Courtois, J., Van der Brempt, X. and Tollenaere, S., 2019. Food-induced anaphylaxis to Tenebrio molitor and allergens implicated. Revue Francaise d'Allergologie 59: 389-393. https://doi. org/10.1016/j.reval.2019.06.001

Belluco, S., Halloran, A. and Ricci, A., 2017. New protein sources and food legislation: the case of edible insects and EU law. Food Security 9: 803-814. https://doi.org/10.1007/s12571-017-0704-0

Boyce, J.A., Assa'ad, A., Burks, A.W., Jones, S.M., Sampson, H.A., Wood, R.A., Plaut, M., Cooper, S.F., Fenton, M.J., Arshad, S.H., Bahna, S.L., Beck, L.A., Byrd-Bredbenner, C., Camargo, C.A., Jr., Eichenfield, L., Furuta, G.T., Hanifin, J.M., Jones, C., Kraft, M., Levy, B.D., Lieberman, P., Luccioli, S., McCall, K.M., Schneider, L.C., Simon, R.A., Simons, F.E.R., Teach, S.J., Yawn, B.P. and Schwaninger, J.M., 2010. Guidelines for the diagnosis and management of food allergy in the United States: report of the NIAID-sponsored expert panel. The Journal of Allergy and Clinical Immunology 126: S1-S58. https://doi.org/10.1016/j.jaci.2010.10.007

Broekman, H., Knulst, A., Den Hartog Jager, S., Monteleone, F., Gaspari, M., De Jong, G., Houben, G. and Verhoeckx, K., 2015. Effect of thermal processing on mealworm allergenicity. Molecular Nutrition and Food Research 59: 1855-1864. https://doi.org/10.1002/ mnfr.201500138

Broekman, H., Knulst, A.C., De Jong, G., Gaspari, M., Den Hartog Jager, C.F., Houben, G.F. and Verhoeckx, K.C.M., 2017a. Is mealworm or shrimp allergy indicative for food allergy to insects? Molecular Nutrition and Food Research 61(9): 1601061. https:// doi.org/10.1002/mnfr.201601061

Broekman, H., Knulst, A.C., Den Hartog Jager, C.F., Van Bilsen, J.H.M., Raymakers, F.M.L., Kruizinga, A.G., Gaspari, M., Gabriele, C., Bruijnzeel-Koomen, C., Houben, G.F. and Verhoeckx, K.C.M., 2017b. Primary respiratory and food allergy to mealworm. The Journal of Allergy and Clinical Immunology 140: 600-603. https:// doi.org/10.1016/j.jaci.2017.01.035

Broekman, H., Verhoeckx, K.C., Jager, C.F.D., Kruizinga, A.G., PronkKleinjan, M., Remington, B.C., Bruijnzeel-Koomen, C.A., Houben, G.F. and Knulst, A.C., 2016. Majority of shrimp-allergic patients are allergic to mealworm. Journal of Allergy and Clinical Immunology 137: 1261-1263. https://doi.org/10.1016/j.jaci.2016.01.005 
Choi, G.S., Shin, Y.S., Kim, J.E., Ye, Y.M. and Park, H.S., 2010. Five cases of food allergy to vegetable worm (Cordyceps sinensis) showing cross-reactivity with silkworm pupae. Allergy: European Journal of Allergy and Clinical Immunology 65: 1196-1197. https://doi. org/10.1111/j.1398-9995.2009.02300.x

Chomchai, S. and Chomchai, C., 2018. Histamine poisoning from insect consumption: an outbreak investigation from Thailand. Clinical Toxicology (Phila) 56: 126-131. https://doi.org/10.1080/ 15563650.2017.1349320

Chomchai, S., Laoraksa, P., Virojvatanakul, P., Boonratana, P. and Chomchai, C., 2020. Prevalence and cluster effect of self-reported allergic reactions among insect consumers. Asian Pacific Journal of Allergy and Immunology 38: 40-46. https://doi.org/10.12932/ ap-220218-0271

De Gier, S. and Verhoeckx, K., 2018. Insect (food) allergy and allergens. Molecular Immunology 100: 82-106. https://doi.org/10.1016/j. molimm.2018.03.015

Epton, M.J., Dilworth, R.J., Smith, W. and Thomas, W.R., 2001. Sensitisation to the lipid-binding apolipophorin allergen Der $\mathrm{p}$ 14 and the peptide Mag-1. International Archives of Allergy and Immunology 124: 57-60. https://doi.org/10.1159/000053668

Francis, F., Doyen, V., Debaugnies, F., Mazzucchelli, G., Caparros, R., Alabi, T., Blecker, C., Haubruge, E. and Corazza, F., 2019. Limited cross reactivity among arginine kinase allergens from mealworm and cricket edible insects. Food Chemistry 276: 714-718. https:// doi.org/10.1016/j.foodchem.2018.10.082

Freye, H.B., 1996. Anaphylaxis to the ingestion and inhalation of Tenebrio molitor (mealworm) and Zophobas morio (superworm). Allergy and Asthma Proceedings 17: 215-219.

Gadisseur, R., Courtois, J., Laouali, S., Van der Brempt, X., Jacquier, J., Cavalier, E., Maizoumbou, D.A., Tollenaere, S. and Hamidou, T., 2019. Sensitization profile of cricket food-allergic or cricket tolerant patients in an entomophagous population in Niamey, Niger. Allergy 74: 253-253.

García, B.E. and Lizaso, M.T., 2011. Cross-reactivity syndromes in food allergy. Journal of Investigational Allergology and Clinical Immunology 21: 162-170; quiz $162 \mathrm{p}$ following 170.

Giuffrida, M.G., Villalta, D., Mistrello, G., Amato, S. and Asero, R., 2014. Shrimp allergy beyond tropomyosin in Italy: clinical relevance of arginine kinase, sarcoplasmic calcium binding protein and hemocyanin. European Annals of Allergy and Clinical Immunology 46: 172-177.

Hall, F. and Liceaga, A., 2020. Effect of microwave-assisted enzymatic hydrolysis of cricket (Gryllodes sigillatus) protein on ACE and DPPIV inhibition and tropomyosin-IgG binding. Journal of Functional Foods 64: 103634. https://doi.org/10.1016/j.jff.2019.103634

Hall, F., Johnson, P.E. and Liceaga, A., 2018. Effect of enzymatic hydrolysis on bioactive properties and allergenicity of cricket (Gryllodes sigillatus) protein. Food Chemistry 262: 39-47. https:// doi.org/10.1016/j.foodchem.2018.04.058

Jeong, K.Y. and Park, J.W., 2020. Insect allergens on the dining table. Current protein and Peptide Science 21: 159-169. https://doi.org/ 10.2174/1389203720666190715091951

Jeong, K.Y., Han, I.S., Lee, J.Y., Park, K.H., Lee, J.H. and Park, J.W., 2017. Role of tropomyosin in silkworm allergy. Molecular Medicine Reports 15: 3264-3270. https://doi.org/10.3892/mmr.2017.6373
Jeong, K.Y., Son, M., Lee, J.Y., Park, K.H., Lee, J.H. and Park, J.W., 2016. Allergenic Characterization of 27-kDa glycoprotein, a novel heat stable allergen, from the pupa of silkworm, Bombyx mori. Journal of Korean Medical Science 31: 18-24. https://doi.org/10.3346/ jkms.2016.31.1.18

Ji, K., Chen, J., Li, M., Liu, Z., Wang, C., Zhan, Z., Wu, X. and Xia, Q., 2009. Anaphylactic shock and lethal anaphylaxis caused by food consumption in China. Trends in Food Science and Technology 20: 227-231. https://doi.org/10.1016/j.tifs.2009.02.004

Ji, K.M., Zhan, Z.K., Chen, J.J. and Liu, Z.G., 2008. Anaphylactic shock caused by silkworm pupa consumption in China. Allergy: European Journal of Allergy and Clinical Immunology 63: 1407-1408. https:// doi.org/10.1111/j.1398-9995.2008.01838.x

Jiang, N., Yin, J., Wen, L. and Li, H., 2016. Characteristics of anaphylaxis in 907 Chinese patients referred to a tertiary allergy center: a retrospective study of 1,952 episodes. Allergy, Asthma \& Immunology Research 8: 353-361. https://doi.org/10.4168/ aair.2016.8.4.353

Jirapongsananuruk, O., Bunsawansong, W., Piyaphanee, N., Visitsunthorn, N., Thongngarm, T. and Vichyanond, P., 2007. Features of patients with anaphylaxis admitted to a university hospital. Annals of Allergy, Asthma, \& Immunology 98: 157-162. https://doi.org/10.1016/s1081-1206(10)60689-8

Jirapongsananuruk, O., Sripramong, C., Pacharn, P., Udompunturak, S., Chinratanapisit, S., Piboonpocanun, S., Visitsunthorn, N. and Vichyanond, P., 2008. Specific allergy to Penaeus monodon (seawater shrimp) or Macrobrachium rosenbergii (freshwater shrimp) in shrimp-allergic children. Clinical \& Experimental Allergy 38: 10381047. https://doi.org/10.1111/j.1365-2222.2008.02979.x

Kamemura, N., Sugimoto, M., Tamehiro, N., Adachi, R., Tomonari, S., Watanabe, T. and Mito, T., 2019. Cross-allergenicity of crustacean and the edible insect Gryllus bimaculatus in patients with shrimp allergy. Molecular Immunology 106: 127-134. https://doi. org/10.1016/j.molimm.2018.12.015

Khan, M.U., Ahmed, I., Lin, H., Li, Z., Costa, J., Mafra, I., Chen, Y. and Wu, Y.N., 2019. Potential efficacy of processing technologies for mitigating crustacean allergenicity. Critical Reviews in Food Science and Nutrition 59: 2807-2830. https://doi.org/10.1080/10 408398.2018.1471658

Klueber, J., Costa, J., Randow, S., Codreanu-Morel, F., Verhoeckx, K., Bindslev-Jensen, C., Ollert, M., Hoffmann-Sommergruber, K., Morisset, M., Holzhauser, T. and Kuehn, A., 2020. Homologous tropomyosins from vertebrate and invertebrate: recombinant calibrator proteins in functional biological assays for tropomyosin allergenicity assessment of novel animal foods. Clinical \& Experimental Allergy 50: 105-116. https://doi.org/10.1111/cea.13503 Kung, S.J., Fenemore, B. and Potter, P.C., 2011. Anaphylaxis to Mopane worms (Imbrasia belina). Annals of Allergy, Asthma and Immunology 106: 538-540. https://doi.org/10.1016/j. anai.2011.02.003

Kung, S.J., Mazhani, L. and Steenhoff, A.P., 2013. Allergy in Botswana. Current Allergy and Clinical Immunology 26: 202-209. 
Le, T.T.K., Nguyen, D.H., Vu, A.T.L., Ruethers, T., Taki, A.C. and Lopata, A.L., 2019. A cross-sectional, population-based study on the prevalence of food allergies among children in two different socioeconomic regions of Vietnam. Pediatric Allergy \& Immunology 30: 348-355. https://doi.org/10.1111/pai.13022

Lee, A.J., Thalayasingam, M. and Lee, B.W., 2013. Food allergy in Asia: how does it compare? Asia Pacific Allergy 3: 3-14. https:// doi.org/10.5415/apallergy.2013.3.1.3

Lee, S.C., Kim, S.R., Park, K.H., Lee, J.H. and Park, J.W., 2019. Clinical features and culprit food allergens of Korean adult food allergy patients: a cross-sectional single-institute study. Allergy, Asthma \& Immunology Research 11: 723-735. https://doi.org/10.4168/ aair.2019.11.5.723

Linares, T., Hernandez, D. and Bartolome, B., 2008. Occupational rhinitis and asthma due to crickets. Annals of Allergy, Asthma and Immunology 100: 566-569.

Liu, Z., Xia, L., Wu, Y., Xia, Q., Chen, J. and Roux, K.H., 2009. Identification and characterization of an arginine kinase as a major allergen from silkworm (Bombyx mori) larvae. International Archives of Allergy and Immunology 150: 8-14. https://doi. org/10.1159/000210375

Manditsera, F.A., Lakemond, C.M.M., Fogliano, V., Zvidzai, C.J. and Luning, P.A., 2018. Consumption patterns of edible insects in rural and urban areas of Zimbabwe: taste, nutritional value and availability are key elements for keeping the insect eating habit. Food Security 10: 561-570. https://doi.org/10.1007/s12571-018-0801-8

Mazzucchelli, G., Holzhauser, T., Cirkovic Velickovic, T., DiazPerales, A., Molina, E., Roncada, P., Rodrigues, P., Verhoeckx, K. and Hoffmann-Sommergruber, K., 2018. Current (food) allergenic risk assessment: is it fit for novel foods? Status quo and identification of gaps. Molecular Nutrition \& Food Research 62: 1700278. https:// doi.org/10.1002/mnfr.201700278

Mejrhit, N., Azdad, O., Chda, A., El Kabbaoui, M., Bousfiha, A., Bencheikh, R., Tazi, A. and Aarab, L., 2017. Evaluation of the sensitivity of Moroccans to shrimp tropomyosin and effect of heating and enzymatic treatments. Food and Agricultural Immunology 28: 969-980. https://doi.org/10.1080/09540105.2017.1323187

Messina, M. and Venter, C., 2020. Recent surveys on food allergy prevalence. Nutrition Today 55: 22-29. https://doi.org/10.1097/ NT.0000000000000389

Migueres, M., Dávila, I., Frati, F., Azpeitia, A., Jeanpetit, Y., LhéritierBarrand, M., Incorvaia, C. and Ciprandi, G., 2014. Types of sensitization to aeroallergens: definitions, prevalences and impact on the diagnosis and treatment of allergic respiratory disease. Clinical and Translational Allergy 4: 16-16. https://doi.org/10.1186/20457022-4-16

Muraro, A., Werfel, T., Hoffmann-Sommergruber, K., Roberts, G., Beyer, K., Bindslev-Jensen, C., Cardona, V., Dubois, A., duToit, G., Eigenmann, P., Fernandez Rivas, M., Halken, S., Hickstein, L., Høst, A., Knol, E., Lack, G., Marchisotto, M.J., Niggemann, B., Nwaru, B.I., Papadopoulos, N.G., Poulsen, L.K., Santos, A.F., Skypala, I., Schoepfer, A., Van Ree, R., Venter, C., Worm, M., Vlieg-Boerstra, B., Panesar, S., De Silva, D., Soares-Weiser, K., Sheikh, A., Ballmer-Weber, B.K., Nilsson, C., De Jong, N.W. and Akdis, C.A., 2014. EAACI food allergy and anaphylaxis guidelines: diagnosis and management of food allergy. Allergy 69: 1008-1025. https://doi.org/10.1111/all.12429
Nebbia, S., Lamberti, C., Giorgis, V., Giuffrida, M.G., Manfredi, M., Marengo, E., Pessione, E., Schiavone, A., Boita, M., Brussino, L., Cavallarin, L. and Rolla, G., 2019. The cockroach allergen-like protein is involved in primary respiratory and food allergy to yellow mealworm (Tenebrio molitor). Clinical \& Experimental Allergy 49: 1379-1382. https://doi.org/10.1111/cea.13461

Okezie, O.A., Kgomotso, K.K. and Letswiti, M.M., 2010. Mopane worm allergy in a 36-year-old woman: a case report. Journal of Medical Case Reports 4: 42. https://doi.org/10.1186/1752-1947-4-42 Pali-Scholl, I., Meinlschmidt, P., Larenas-Linnemann, D., Purschke, B., Hofstetter, G., Rodriguez-Monroy, F.A., Einhorn, L., MothesLuksch, N., Jensen-Jarolim, E. and Jager, H., 2019. Edible insects: cross-recognition of IgE from crustacean and house dust mite allergic patients, and reduction of allergenicity by food processing. World Allergy Organization J 12: 100006. https://doi.org/10.1016/j. waojou.2018.10.001

Palmer, L.K., Marsh, J.T., Lu, M., Goodman, R.E., Zeece, M.G. and Johnson, P.E., 2020. Shellfish tropomyosin IgE cross-reactivity differs among edible insect species. Molecular Nutrition and Food Research 64: e1900923. https://doi.org/10.1002/mnfr.201900923

Pennisi, E., 2015. All in the (bigger) family. Science 347: 220. https:// doi.org/10.1126/science.347.6219.220

Phiriyangkul, P., Srinroch, C., Srisomsap, C., Chokchaichamnankit, D. and Punyarit, P., 2015. Effect of food thermal processing on allergenicity proteins in Bombay locust (Patanga Succincta). International Journal of Food Engineering 1: 23-28. https://doi. org/10.18178/ijfe.1.1.23-28

Piatt, J.D., 2005. Case report: urticaria following intentional ingestion of cicadas. American Family Physician 71: 2048, 2050.

Piromrat, K., Chinratanapisit, S. and Trathong, S., 2008. Anaphylaxis in an emergency department: a 2-year study in a tertiary-care hospital. Asian Pacific Journal of Allergy and Immunology 26: 121-128.

Pomés, A., Mueller, G.A., Randall, T.A., Chapman, M.D. and Arruda, L.K., 2017. New insights into cockroach allergens. Current Allergy and Asthma Reports 17: 25-25. https://doi.org/10.1007/s11882017-0694-1

Rangkakulnuwat, P., Sutham, K. and Lao-Araya, M., 2020. Anaphylaxis: ten-year retrospective study from a tertiary-care hospital in Asia. Asian Pacific Journal of Allergy and Immunology 38: 31-39. https:// doi.org/10.12932/ap-210318-0284

Ribeiro, J.C., Cunha, L.M., Sousa-Pinto, B. and Fonseca, J., 2018. Allergic risks of consuming edible insects: a systematic review. Molecular Nutrition and Food Research 62: 30. https://doi. org/10.1002/mnfr.201700030

Sokol, W.N., Wünschmann, S. and Agah, S., 2017. Grasshopper anaphylaxis in patients allergic to dust mite, cockroach, and crustaceans: is tropomyosin the cause? Annals of Allergy, Asthma and Immunology 119: 91-92. https://doi.org/10.1016/j. anai.2017.05.007

Stanhope, J., Carver, S. and Weinstein, P., 2015. The risky business of being an entomologist: a systematic review. Environmental Research 140: 619-633. https://doi.org/10.1016/j.envres.2015.05.025

Taylor, G. and Wang, N., 2018. Entomophagy and allergies: a study of the prevalence of entomophagy and related allergies in a population living in North-Eastern Thailand. Bioscience Horizons 11. https:// doi.org/10.1093/biohorizons/hzy003 
Van Broekhoven, S., Bastiaan-Net, S., De Jong, N.W. and Wichers, H.J., 2016. Influence of processing and in vitro digestion on the allergic cross-reactivity of three mealworm species. Food Chemistry 196: 1075-1083. https://doi.org/10.1016/j.foodchem.2015.10.033

Verhoeckx, K., Broekman, H., Knulst, A. and Houben, G., 2016. Allergenicity assessment strategy for novel food proteins and protein sources. Regulatory Toxicology and Pharmacology 79: 118-124. https://doi.org/10.1016/j.yrtph.2016.03.016

Wai, C.Y.Y., Leung, N.Y.H., Chu, K.H., Leung, P.S.C., Leung, A.S.Y., Wong, G.W.K. and Leung, T.F., 2020. Overcoming shellfish allergy: how far have we come? International Journal of Molecular Sciences 21: 2234. https://doi.org/10.3390/ijms21062234

Wang, J. and Sampson, H.A., 2011. Food allergy. The Journal of clinical investigation 121: 827-835. https://doi.org/10.1172/JCI45434

Wang, H., Hu, W., Liang, Z., Zeng, L., Li, J., Yan, H., Yang, P., Liu, Z. and Wang, L., 2016. Thiol peroxiredoxin, a novel allergen from Bombyx mori, modulates functions of macrophages and dendritic cells. American Journal of Translational Research 8: 5320-5329.

Westerhout, J., Krone, T., Snippe, A., Babe, L., McClain, S., Ladics, G.S., Houben, G.F. and Verhoeckx, K.C., 2019. Allergenicity prediction of novel and modified proteins: Not a mission impossible! Development of a random forest allergenicity prediction model. Regulatory Toxicology and Pharmacology 107: 104422. https:// doi.org/10.1016/j.yrtph.2019.104422

Wong, L., Huang, C.H. and Lee, B.W., 2016. Shellfish and house dust mite allergies: is the link tropomyosin? Allergy, Asthma \& Immunology Research 8: 101-106. 10.4168/aair.2016.8.2.101
Wong, L., Tham, E.H. and Lee, B.W., 2019. An update on shellfish allergy. Current Opinion in Allergy and Clinical Immunology 19: 236-242. https://doi.org/10.1097/aci.0000000000000532

World Health Organization and International Union of Immunological Societies (WHO/IUIS) Allergen Nomenclature Sub-committee, 2020. Allergen nomenclature. Available at: http://www.allergen.org.

Wu, M.L., Yang, C.C., Yang, G.Y., Ger, J. and Deng, J.F., 1997. Scombroid fish poisoning: an overlooked marine food poisoning. Veterinary and human toxicology 39: 236-241.

Yang, Z., Zhao, J., Wei, N., Feng, M., Xian, M., Shi, X., Zheng, Z., Su, Q., Wong, G.W.K. and Li, J., 2018. Cockroach is a major cross-reactive allergen source in shrimp-sensitized rural children in southern China. Allergy 73: 585-592. https://doi.org/10.1111/all.13341

Yi, L., Van Boekel, M.A.J.S., Boeren, S. and Lakemond, C.M.M., 2016. Protein identification and in vitro digestion of fractions from Tenebrio molitor. European Food Research and Technology 242: 1285-1297. https://doi.org/10.1007/s00217-015-2632-6

Zhao, X., Li, L., Kuang, Z., Luo, G. and Li, B., 2015. Proteomic and immunological identification of two new allergens from silkworm (Bombyx mori L.) pupae. Central European Journal of Immunology 40: 30-34. https://doi.org/10.5114/ceji.2015.50830

Zuo, J., Lei, M., Yang, R. and Liu, Z., 2015. Bom m 9 from Bombyx mori is a novel protein related to asthma. Microbiology and Immunology 59: 410-418. https://doi.org/10.1111/1348-0421.12271 
